Nathaniel W. Yang, MD

Department of Otorhinolaryngology College of Medicine - Philippine General Hospital University of the Philippines Manila

Philippine National Ear Institute National Institutes of Health University of the Philippines Manila

Department of Otolaryngology Head and Neck Surgery Far Eastern University - Nicanor Reyes Memorial Foundation Institute of Medicine
Correspondence: Dr. Nathaniel W. Yang Department of Otorhinolaryngology Ward 10, Philippine General Hospital Taft Ave., Ermita, Manila 1000

Philippines

Phone: (632) 5264360

Email: <nwyang@gmx.net>

Reprints will not be available from the author.

The author declared that this represents original material that is not being considered for publication or has not been published or accepted for publication elsewhere, in full or in part, in print or electronic media; that the manuscript has been read and approved by the author, that the requirements for authorship have been met by the author, and that the author believes that the manuscript represents honest work.

Disclosures: The author signed a disclosure that there are no financial or other (including personal) relationships, intellectual passion, political or religious beliefs, and institutional affiliations that might lead to a conflict of interest.

\section{When is a Vestibular Aqueduct Enlarged?}

A 10-year-old boy with bilateral moderate sensorineural hearing loss underwent computerized tomographic (CT) imaging (GE Brightspeed, Wisconsin, USA) of the temporal bone as part of the work-up to determine the etiology of his condition. The formal radiologic interpretation of the scan stated that the vestibular aqueducts were not enlarged. However, independent review of the axial CT images appeared to indicate the presence of enlarged vestibular aqueducts. (Figure 1) This can be contrasted with a scan from another patient with no evidence of sensorineural hearing loss. (Figure 2)

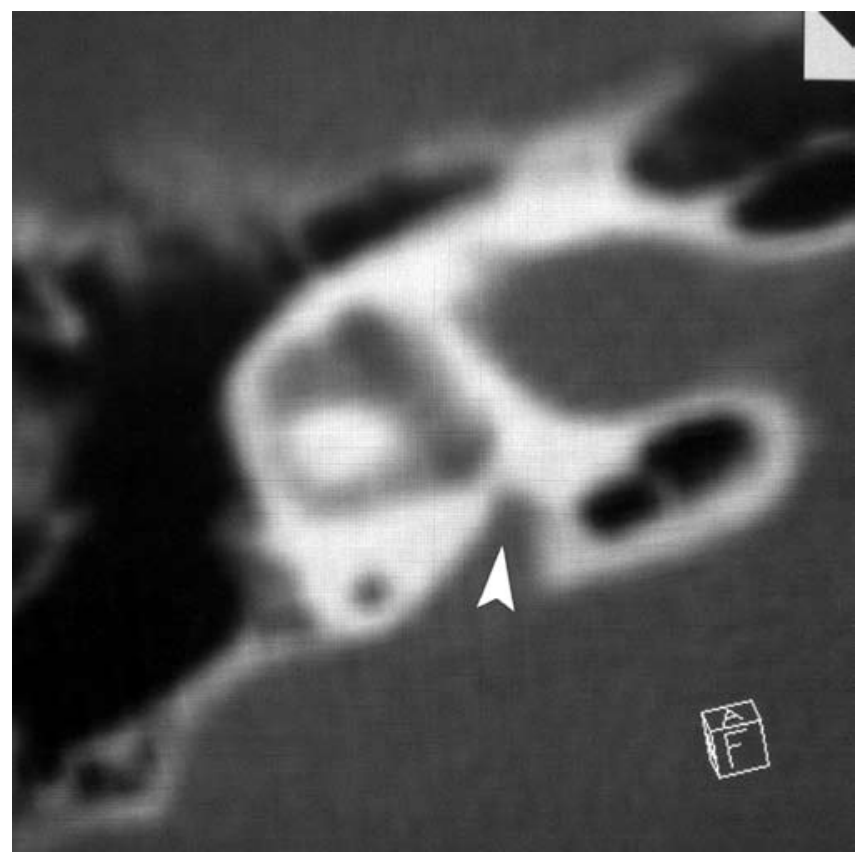

Figure 1. Axial CT image of the patient's right temporal bone showing an apparently enlarged vestibular aqueduct (white arrowhead)

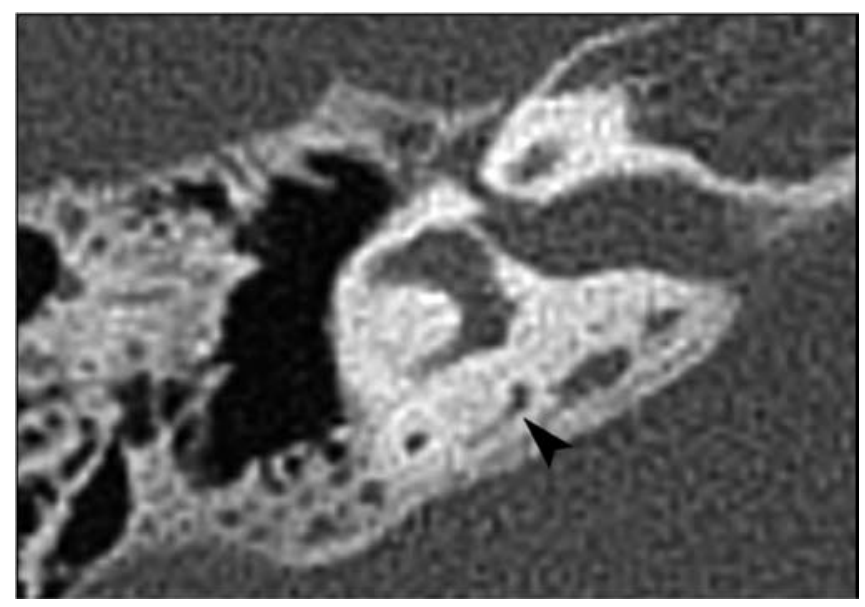

Figure 2. Axial CT image showing a normal-sized vestibular aqueduct (black arrowhead) 
What can explain the discrepancy between the two?

If simple visual inspection of the vestibular aqueduct (VA) can lead to conflicting interpretations, then what radiographic parameters can be used to resolve the issue? Is there a more objective means of determining the presence of a clinically significant vestibular aqueduct enlargement?

In 1978, Valvasorri and Clemis' first described an association between congenital sensorineural hearing loss and an abnormality in vestibular aqueduct anatomy which they labelled as the "large vestibular aqueduct syndrome." In this landmark study that utilized hypocycloidal polytomographic temporal bone studies, they proposed that a vestibular aqueduct is enlarged when its midpoint diameter is greater than $1.5 \mathrm{~mm}$. Although this parameter is generally considered to be the defining characteristic of the condition, one must realize that this measurement was based on less accurate imaging technology and measurement tools. Contemporary studies utilize highresolution $\mathrm{CT}$ imaging with digital workstation measurement software to evaluate vestibular aqueduct anatomy. Currently, the two most commonly used radiographic parameters are the VA midpoint (MP) width and the VA opercular (OP) width. (Figure 3)

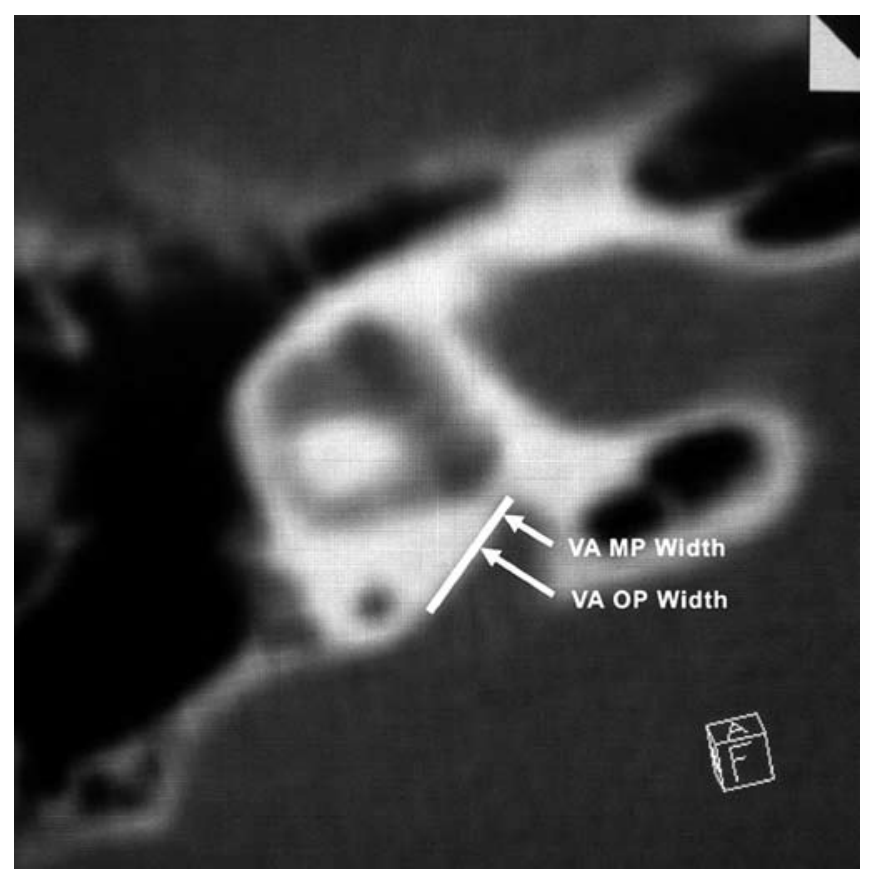

Figure 3. Clinically measured vestibular aqueduct dimensions on Axial CT

The vestibular aqueduct opercular (OP) width is measured from the edge of the operculum to the posterior surface of the petrous bone, using a line perpendicular to the posterior surface of the petrous bone. The vestibular aqueduct midpoint (MP) width is measured halfway between the origin of the vestibular aqueduct or posterior wall of the vestibule and the point at which the opercular width is measured.
More recently, Boston et al. $^{2}$ in 2007 published normative values for these parameters based on a study population of 73 children without known sensorineural hearing loss. They considered a vestibular aqueduct enlarged when one or both of the measured widths were above the $95^{\text {th }}$ percentile of the normal study group measurements. On this basis, a VA midpoint width of $>0.9 \mathrm{~mm}$ and/or a VA opercular width of $>1.9 \mathrm{~mm}$ was the criteria established to define an enlarged vestibular aqueduct.

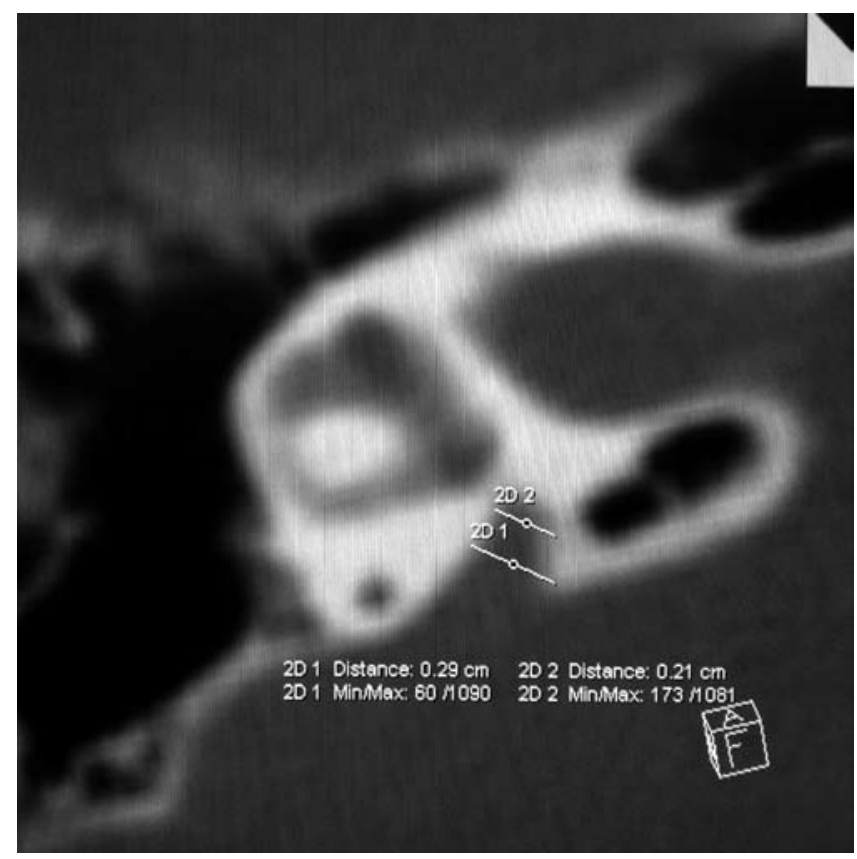

Figure 4. Measurement of the patient's right vestibular aqueduct on Axial CT using radiologic workstation software (syngo $C T$, Siemens AG, Berlin and München).

The vestibular aqueduct opercular width (2D 1) measured $0.29 \mathrm{~cm}$. The vestibular aqueduct midpoint width (2D 2) measured $0.21 \mathrm{~cm}$.

The patient's measured vestibular aqueduct midpoint width on the right was $2.1 \mathrm{~mm}$, while the vestibular aqueduct opercular width was $2.9 \mathrm{~mm}$. (Figure 4) These measurements, when evaluated against either the original Valvassori criteria or the newer criteria of Boston et al., confirm what was visually apparent- the presence of a clinically significant enlargement of the vestibular aqueduct as the etiology of the patient's sensorineural hearing loss.

\footnotetext{
REFERENCES

1. Valvassori GE, Clemis JD. The large vestibular aqueduct syndrome. Laryngoscope 1978 May; 88(5): 723-728.

2. Boston M, Halstead M, Meinzen-Derr J, Bean J, Vijavasekaran S, Arjmand $\mathrm{E}_{\text {, et al. The }}$ large vestibular aqueduct: a new definition based on audiologic and computed tomography correlation. Otolaryngol Head Neck Surg 2007 Jun; 136(6): 972-977.
} 